TITLE:

\title{
Interaction studies in Japanese primatology: their scope, uniqueness, and the future.
}

AUTHOR(S):

Nakamura, Michio

CITATION:

Nakamura, Michio. Interaction studies in Japanese primatology: their scope, uniqueness, and the future.. Primates 2009, 50(2): 142-152

ISSUE DATE:

2009-04

URL:

http://hdl.handle.net/2433/173371

\section{RIGHT:}

The final publication is available at link.springer.com; This is not the published version. Please cite only the published version.; この論文は 出版社版でありません。引用の際には出版社版をご確認ご利用くださ い。 
NOTICE: This is the author's version of the following article.

Nakamura M (2009) Interaction studies in Japanese primatology: Their scope, uniqueness, and the future. Primates 50:142-152.

DOI: $10.1007 /$ s10329-009-0133-6.

(C) Japan Monkey Centre and Springer-Verlag. The original publication is available on SpringerLink at http://link.springer.de

\title{
Interaction studies in Japanese primatology: Their scope, uniqueness, and the future
}

\author{
Michio Nakamura \\ Wildlife Research Center, Kyoto University
}

\begin{abstract}
This paper aims to review social interaction studies in Japanese primatology, in order to introduce their utility into the current framework of primatology and their potential for understanding primate sociality. In the first part, I introduce some of the achievements in the field of Japanese primatology. It is a well-known fact that Japanese primatology, in its initial phases, strongly focused on society and sociality in nonhuman primates with respect to human society and sociality. Although Jun'ichiro Itani's theory on the evolution of social structure significantly influenced some of the Japanese primatologists, it had a comparatively minor impact on the West. As Itani himself admitted, he only treated the so-called "hardware" of society and did not deal with its "software" comprehensively, although he understood its importance and even provided some insightful ideas. In the latter part of the paper, I introduce some of the studies that directly dealt with the social interactions of primates and that were written mostly in Japanese. As compared to works in standard primatology, many of these papers were descriptive. This is because interaction cannot be decomposed into individual behaviors; thus, we have to focus on interaction itself. Finally, I argue that we need to explore the methodology for describing the lively and dynamic aspects of primate sociality.
\end{abstract}

Key Words: social interaction, Japanese primatology, dynamism of society, qualitative description

\section{Why Primates Interest Us}

Imagine a child visiting a zoo with his parents. He looks into the monkey enclosure and is attracted to what he sees there. Monkeys and apes always interest a novice. It appears that the monkeys' social interactions instantly attract children toward them. The child neither knows about the social structure of the monkey species nor does he know how a particular behavior can be adaptive or beneficial in the sociobiological sense. Therefore, it is not such knowledge that makes the monkeys' interactions appear interesting to him. Although they may notice that monkeys are somewhat similar to humans, children do not know and are not concerned about whether monkeys are taxonomically or genetically close to humans. Of course, for professional researchers, the structured societies of primates or behaviors that can be suitably and parsimoniously explained using individual reproductive strategies are the attractive features for academics. However, this does not imply that the sociality of primates is not understandable or interesting without such current academic frameworks. Researchers do (or did) have the same naïve interest as that of the child mentioned above, and this initial interest could be a possible reason their de- ciding to become primatologists. However, as scientists, they can no longer pursue the same naïve interest; rather, they have to place themselves in the current academic frameworks.

Nevertheless, I believe that such a naïve interest should not be abandoned. It is important for researchers to visit the field in order to gain first-hand impressions. However, may they report the vivid impressions they actually observe in nature? Do primatologists actually focus on interesting aspects of primates, such as their lively social interactions, which even a child immediately notices? In other words, can primatologists write "ethnographies" about target species or societies in the same manner that anthropologists write about their targets? The answer can be both yes and no. It is "yes" because early primatologists wrote "ethnographies" in the form of books for general public (e.g., Itani 1954; Goodall 1971; Nishida 1973). In such books, the lively interactions of monkeys and apes were vividly described and still retain their brilliance. Although it is easy to say that these earlier descriptions were not purely academic or scientific, it is true that such classic primate "ethnographies" help us understand the reality of the social world of monkeys and apes even beyond species (Sugawara 2002). The answer is "no" because 
today, this method of describing primate behaviors is becoming devalued. At the very least, the methodology that observes and describes the actual behaviors of monkeys and apes now seems to be regarded as old-fashioned or even nonscientific. Now, researchers have to define and to categorize behavioral patterns in order to make them suitable for statistical testing and sometimes they provide only statistical values in their scientific papers. I sometimes face difficulties in understanding a particular categorized behavior, because authors only summarize the subtle variations to a single behavioral category and seldom provide a rational explanation for such categorization. In such cases, it can be said that the reality of the particular behavior is lost.

Although lively social interactions are not limited to primates, it is often easier to observe and record such interactions in primates than in other animals because most primates live in gregarious and stable social groups usually terrestrial (as opposed to aquatic) and diurnal. This paper provides an overview of the history of Japanese primatology from the standpoint that the fascinating aspect of primate sociality lies in their vivid social interactions. I will mainly review the published literature on primate societies and social interactions written in Japanese. There are three reasons for this: First, this special issue of Primates is meant to commemorate the 60th anniversary of Japanese primatology; thus, it is appropriate to focus on this field. Second, as a native Japanese speaker, I am aware that papers written only in Japanese or papers that can only be expressed in Japanese contain unique ideas and important observations. I will not be able to introduce all the ideas that even their original authors could not express in English; however, it will still be useful to introduce these ideas at least to some extent. Third, studies based on such detailed descriptions of social interactions are mostly written in Japanese (or in English by Japanese primatologists). This may be because, as is often pointed out (e.g., Asquith 2000; Takasaki 2000), Japanese (particularly traditional Japanese) primatology and Western primatology adopted rather different approaches (but see McGrew (2007) who emphasized the links rather than differences between Japanese and Western primatology). Today, many Japanese researchers adopt the Western approach, perhaps because the Japanese academic world now requires them to write papers in international journals. Ideally, the quality of a study should not be judged by the language in which it is written but instead purely by its content. However, in Japan, it is often assumed that a paper published in an English journal is superior to that published in a Japanese one (of course, the citation index is usually higher in the former owing to its wider readership). Thus, young Japanese researchers avoid such Japanese approaches and intentionally or unintentionally adopt the Western approach, which is more readily accepted in international journals.

Theoretical background of Japanese primatology, especially the focus on sociology of primates, is often attributed to Kinji Imanishi (e.g., 1941, 1951, 1966) and his ideas have been relatively well introduced in
English language (e.g., de Waal 2001, 2003; Asquith 2002; Nakamura and Nishida 2006; Matsuzawa and McGrew 2008). Therefore, in order to avoid repetition, I mention little about Imanishi's ideas but instead start from discourse made by Jun'ichiro Itani whose ideas have been relatively less introduced to English readership. Some, or maybe majority, of Japanese primatologists may not be completely happy with my understanding of the history on Japanese primatology and its interpretation. However, in the context of social interaction studies, I believe my standpoint will provide some useful insights to the future research perspectives.

\section{Achievements in the Field of Early Japanese Pri- matology}

When research began to be undertaken in the field of Japanese primatology, understanding societies or sociality was the most important objective (Imanishi 1957; Itani 1985a). It is often said that traditional Japanese primatology was concerned with sociology rather than biology (e.g., Muroyama 1998). Although some Japanese researchers have given more weight to biology (e.g., Sugiyama 2000), many primatologists, particularly those from the Kyoto School (sensu Takasaki 2000), attempted to understand the societies of living things without limiting their methodology to purely biological concerns. The following statement by Imanishi appropriately indicates the situation: "What I want to conduct is research on the historicity of animal societies that can only be understood by accumulating thorough records. Such records can only be obtained by describing the dynamism of the societies in place of the animals themselves who do not have language or letters to do so" (Imanishi 1960, my translation).

One of the well-known achievements in the field of Japanese primatology that is recognized worldwide is the prediction and discovery of primate cultures (Imanishi 1952; Kawamura 1959; Kawai 1965; Itani and Nishimura 1973; Nishida 1987; also see Nakamura and Nishida 2006 for a review). Such early studies on primate culture are highly praised by Western primatologists (de Waal 2001; McGrew 2004), and the famous paper on sweet potato washing (Kawai 1965) is often cited by Western researchers even today (e.g., van Schaik et al. 1999; Rendell and Whitehead 2001; Boesch 2003).

Apart from such well-recognized achievements, studies on the evolution of primate social structures by Itani $(1977,1980 a, 1981,1987)$, who emphasized the importance of phylogeny and some type of fundamental "rules" or "institutions" for societies, had a certain influence to some Japanese primatologists (e.g., Yamagiwa 1994; Furuichi 1999; Kuroda 1999); however, they did not seem to get much attention in the West although some part of the idea was also published in English (Itani 1977, 1985b). Itani's discussions on primate social structure both influenced and were influenced by the elucidation of the social structures of great apes by some Japanese researchers (Nishida 1968; 
Kuroda 1979; Sugiyama and Koman 1979; Kano 1982).

Itani's methodology, which discusses the evolutionary pathway by understanding society as a structure using basic data such as group composition, number of group members, and the transferring sex, became a trend at least in Japan. Many Japanese primatologists once devoted themselves to the search for primate social structures and their evolution. Although this trend declined with the rise of socioecology, some researchers still try to develop Itani's theory on the evolution of social structure within the framework of socioecology (e.g., Yamagiwa 1999; Furuichi 2006).

Itani's theory on social structure superficially resembles current socioecology in some aspects such that both grasp a society as a structure in relation to the spatiotemporal dispersal pattern of different sexes, but differs in others. In socioecology, social organization is regarded as the outcome of the strategies employed by individuals to meet their basic requirements and can be regarded as an instrument used by individuals that achieves the social structure (Wrangham 1980; van Schaik and van Hooff 1983; Sterck et al. 1997). On the other hand, Itani's social structure is more group-based and phylogenetic continuity and group "heredity" (i.e., transgenerational conservation of characteristics of a society) are considered to be important.

Following the rise of socioecology, there were critiques that phylogeny has to be considered in addition to current ecological factors (Rendall and Di Fiore 1995; Foley 1996). Although Itani had emphasized the importance of phylogeny with respect to social structures more than 15 years before, Western scholars did not grasp this importance, or if they did, they disregarded it.

\section{"Software” of Society and Anti-structure}

As mentioned above, although social structure theory was once dominant in sociological studies of primates in Japan, a slightly different movement began in the period from the late 1970 s to the 1980 s. This period corresponds to that when Itani basically had completed his work on primate social structure and shifted his main interest to studies of the ecological anthropology of farmers, hunter-gatherers, and pastoralists who were still considerably dependent on nature (e.g., Itani 1980b). Some young researchers and students studying nonhuman primates began to target social interaction itself rather than social structure as the main theme of their studies. Itani (1988) once dubbed this small group of people an "Interaction School", himself not being directly involved in it.

Moreover, Itani himself admitted that although he had been studying the so-called "hardware" of society, further research on the "software" of society was required thereafter (Itani 1987). Here by "hardware" he meant structure of a society, and by "software" behaviors and social interactions that make co-existence of individuals possible and that make the social structure.
Although his main discussions on primate societies concerned hardware, he sometimes also discussed the software of society; one such discussion was "Discourse on the Origin of Equality" (Itani 1986), which dealt with the equality and inequality in the society of primates, including humans. This work was definitely inspired by "Discourse on the Origin of Inequality" by Rousseau (1755). As is widely known, Rousseau argued that all primitive natural men were equal and anonymous; social inequality then followed as society evolved. Using the knowledge obtained from primate studies at that time, Itani argued that Rousseau's concept of initial equality should be traced back to elemental societies of nonhumans, such as those of solitary prosimians, and termed such societies those of "equipotency." This type of society is based on individuals who avoid each other and was the prior stage to the societies that ensured equality and inequality through social interactions. As the next step, he considered a pair type of social unit that can be found in various clades of primates and termed it a society of "pristine equality." Societies with a larger group size and with female philopatry, such as those of Japanese macaques, were regarded as societies of "pristine inequality." This type of society, Itani argued, was based on the principle of matrilineal kinship and strict dominant-subordinate interactions. In such pristine inequality, when individuals act as if such inequality does not exist, "conditional equality" emerges. Good examples of such conditional equality are observed in social play or food sharing in great apes (Itani 1986).

Another important but lesser known discourse on the software of society by Itani was "Behaviors that Make Social Structure" (Itani 1981). In this paper, he first admitted that any behavior can be described only by using language, and by analyzing the verbs used in the primatological literature, he classified eight strata of behaviors (brief English introduction by Nakamura, in press). Itani emphasized that affirmative/negative and active/passive forms of a verb "forgive", i.e., a quadrant of "forgive/not forgive/be forgiven/be not forgiven" were critically important in the formation of social structure (it should be noted that the equivalent Japanese verb for "forgive" also have a nuance of "tolerate").

Another important concept that is relevant but cannot really be categorized as software is "anti-structure" (Itani 1991). This concept can be used with reference to solitary males among Japanese monkeys (Nishida 1966) or all-male groups of gorillas (Yamagiwa 1987), which is in contrast to the gregarious and well-structured (as observed in the dominance hierarchy) nature of bisexual groups. After focusing on the structure of primate societies, Itani later stated that an individual primate can move from structure to anti-structure and then back to structure; therefore, structure and anti-structure should be regarded as a whole set in the context of the formation of a society of one species. This idea is important in that Itani understood that his discourse on social structure was not completed and required another dimension. 
As discussed earlier, Itani, who had one of the significant influences on the theoretical aspect of Japanese primatology after Kinji Imanishi, pointed out the importance of software, although he mostly devoted his works to tracing the evolution of the hardware of society or the social structure. Barring the fine-grained descriptions of Japanese monkeys in the early period (e.g., Itani 1954), he conducted no study of social interactions of primates by himself. However, he shifted to studies of ecological anthropology and later to a macroscopic study on African vegetation in relation to human evolution (Itani and Terashima 2001).

\section{What is Interaction?}

In current studies in primatology, the terms "social interaction," "social relationships," and "social structure" mostly are used according to the formulation by Hinde (1976), in which multiple interactions form a relationship and multiple relationships create a structure. Therefore, interaction between two individuals is the basic element of a social structure. Hinde also emphasized the necessity of generalization with regard to the same characteristics and search for principles in order to provide causal or functional explanations. He stated that "interactions need be considered only briefly," and he formulated social interactions simply as "A does $\mathrm{X}$ to B" or "A does X to B and B responds with Y."

In the usual usage of the word, interaction is "a kind of action that occurs as two or more objects have an effect upon one another" (Wikipedia 2008a), where the objects do not have to be living organisms. In sociology, the usage of "social interaction" changes slightly, for instance, it can refer to "a dynamic, changing sequence of social actions between individuals who modify their actions and reactions according to the actions by their interaction partner" (Wikipedia 2008b). From this definition, it is understood that social interaction comprises two or more actions ( $\approx$ behaviors); however, it cannot be decomposed into actions. More precisely, the very nature of an interaction cannot be understood if we decompose it into actions. Therefore, in order to study interactions, we have to target interaction as a whole set. An individual's mental state (e.g., motivation or intention), physiological state (e.g., hormones), or genetic background for a particular action or behavior is definitely related to the occurrence of an interaction. However, the nature of interaction cannot be understood by classifying it into such different lower levels.

Although Hinde (1976) also pointed this out by stating that "it has properties that are not present in the behavior of either participant alone," his above formulation appears to merely cover social behavior rather than social interaction because "does X" can be attributed to the responsibility of individual A, while B can only be a passive recipient. Additionally, the first formulation only includes a one-way action from A to B and does not include B's reaction. Even if B's reaction $\mathrm{Y}$ is included, it only appears to be an interchange of behaviors. Therefore, this formulation does not seem to be good enough.

However, it is not easy to formulate such interaction in a simple manner. The interaction between $\mathrm{A}$ and B may be described as follows:

"...A does $\mathrm{X}$ to $\mathrm{B}, \mathrm{B}$ does $\mathrm{Y}$ to $\mathrm{A}$ in relevance to $\mathrm{X}, \mathrm{A}$ does $\mathrm{Z}$ to $\mathrm{B}$ in relevance to $\mathrm{Y}$...”

The important point here is that the sum of $\mathrm{X}, \mathrm{Y}$, and $\mathrm{Z}$ can never represent the complete interaction. Although we have to extract some fragment of a dynamically changing interaction in order to record or describe it, that part cannot be independent from the background. Moreover, it is important to note that X, Y, and $Z$ do not have to be a causal chain nor do they have to linearly proceed in this order. Even when A does X, $\mathrm{B}$ does not always have to do Y. The occurrence of $\mathrm{X}$ may affect that of $Y$ only in such a way that $X$ narrows the relevant actions following it, and there is always the possibility that an action other than $\mathrm{Y}$ will be performed in place of Y.

The indecomposability of a social interaction into actions may be related to the holistic idea of Japanese primatology in its earlier phase (e.g., Kuroda 1986; Takasaki 1999). Although the level is different, a society itself has a holistic characteristic that cannot be understood by decomposing it to lower levels. This is in contrast with Hinde's (1976) idea that the social structure can be decomposed to lower elements. Because the standard of Western natural science basically relates to decomposing the world to some elements in order to understand it, such a holistic view may not be acceptable in the mainstream of primatology, which focuses on biology (biological anthropology, behavioral ecology, etc.), a subdivision of natural science. There seems to be a general tendency that Westerners see a "tree" while Asians see a "forest" (Nisbett 2003). This difference merely corresponds to two different aspects of one phenomenon and neither is superior to the other. However, in Japanese primatology, following the introduction of sociobiology, several researchers began to question this holistic view of early Japanese primatology (e.g., Sawaguchi and Kudo 1987). Many of these researchers now attempt to only see a "tree," as if the Western way of looking at nature is the only correct way.

It is now widely recognized that the phenomenona occurring in complex systems cannot simply be decomposed to lower levels (e.g., Kauffman 1995). An alternative approach to reductionism is needed for such complex systems, although it is sometimes difficult to develop such an approach. Anyone who studies primates probably would agree that primate society is a complex system. Such views that regard the holistic aspects of sociality are slowly gaining acceptance as a result of the recent increase in interest in primate cultures. Although it is obvious that an individual plays a role in the formation of culture, this does not imply that a culture can be decomposed to individual behaviors. The actions of an individual cannot be termed as culture; rather, the term can be applied to the collective 
actions of individuals (e.g., see McGrew 2004).

\section{Observability}

Although an interaction has holistic and noncausal characteristics, it is still observable. This is in contrast to the fact that a social relationship or a social structure can never be observed directly. A relationship or a structure is a conceptual scheme that observers abstract and construct after the accumulation of behavioral data or interactions over time. Therefore, observers inevitably dissect the ever-changing social world within a time-frame in order to determine the status of relationships and structures.

A dominant-subordinate relationship can, for example, be observed in the case of individual A continuously showing subordination to individual B (as in the pant grunting of chimpanzees: Bygott 1979). Usually, we do not use the term dominant-subordinate relationship if there is only one occasion of subordinate behavior by A toward $\mathrm{B}$, because it is possible that on other occasions, B might show subordination to A or otherwise, dominance among $\mathrm{A}$ and $\mathrm{B}$ is ambiguous (it may depend on situations). Therefore, we need a defined time-frame in order to abstract such a relationship; however, the decision regarding the time span usually depends on the observer. We shall consider the following example:

Period 1: A shows subordination to $\mathrm{B}$.

Period 2: B shows subordination to A.

Period 3: A shows subordination to B.

If each period is, for instance, 10 minutes long, we will tend to think that there is no stable relationship between the two (the dominant-subordinate relationship is ambiguous). However, if each period is several years long, we will then observe the stable relationship within each period and say that reversals of the dominant-subordinate relationship have occurred. This simple example shows that we need some time-frame in order to abstract relationships; however, the basis for this time frame is arbitrarily fixed.

The same observation can be made with regard to whether the relationship has changed or no relationship has been established at all. In this sense, a relationship is not a phenomenon that we can directly observe but a conceptual construction by the observer. There could be a counter-argument that there is no such problem if the definition of the time period is set prior to observation. It is true that with such definition, we can determine when to dissect our data; however, this does not help solve this problem because such definition for a relationship can only be arbitrarily fixed by the researcher.

The above discussion is also true for social structure. Structure is not an observable phenomenon; rather, it is only identified by an observer on the basis of changing membership and interactions among individuals within a particular time-span.

Interaction also needs a time-span in order to be identified and the method of setting this time-frame again depends on the observer. However, interaction is different from the above two concepts in that it can be observed continuously by an observer when it is occurring; further, it cannot be understood unless such observation is conducted. Therefore, the only phenomenon observable to the observer in reality is each interaction, and it is the observer who measures such interactions by assuming that different interactions occur at different times and that they are of the "same" type.

It seems to me that in current primatology, terms such as social relationships or structure are easily adopted without thorough consideration of what the earlier researchers abstracted from their observations. It may not be wise to consider the implications of the terms or the authors' intent of the earlier definitions. However, I believe that we should examine the real contents of relationships or structures from the viewpoint of the concrete level of interactions in order to gain a better understanding of primate sociality.

\section{Dynamism of the Social World}

The social world is always dynamic. This dynamism attracts both researchers and children at the zoo toward primate society. However, at the same time, this dynamism makes it difficult for the observer to describe social phenomena. Researchers have to describe interactions by using language (cf. Itani 1981); however, when we do so, the descriptions become static. This may be because although language itself is a dynamic system, written language used in such descriptions is usually static.

In the ethological sense, a behavior is determined by classifying the participants in an interaction as an active performer and a passive recipient, and the behavior is treated as if it belongs to the performer. We can use check-sheets to record particular social behaviors with one-zero sampling only because we discard the dynamic aspects of actual interactions and their relevance to the participants in each context. When we try to grasp the interaction without discarding its dynamism in reality, it sometimes results in long descriptions of events that may be regarded as being too wordy.

For example, Mori (1994) conducted a "story analysis" on the social change process of bonobos at Wamba. Here, by a story he meant a description and its interpretation of consecutively occurring social events. When one pools multiple social interactions for qualitative analysis, e.g., to calculate relative frequency, he/she assumes that each interaction is independent with each other. Instead, story analysis assumes that each events are not independent but in causal relationships. By conducting this analysis, Mori attempted to substantiate the anthropomorphic expressions often seen in Japanese literature.

Itoh (2003) described the interactions constantly seen in the fission-fusion of chimpanzees in the Mahale Mountains. Although fission-fusion is regarded as 
unique characteristics of chimpanzee societies, it is often considered only in relation to party size and composition (another construction that has been analyzed by researchers), which is not really fission-fusion but only an outcome of it. Itoh's description is the first attempt to describe the ongoing mechanism of the dynamic fission-fusion phenomenon in chimpanzees. Her description indicates that although salient behaviors such as greeting or grooming do not always have to occur, slight movements involving individuals who meet and part always take place. She argued that what is observed as a contour of a group or a party is made through everlasting movements of interacting individuals and lags (neither perfect coordination nor complete irrelevance) among such movements.

Adachi (2003) raised the objection that the term "society" is commonly limited to individuals of one species. She described the mixed-species association of cercopithecid monkeys in the Taï Forest in order to discuss fission-fusion across species and their interspecific interactions. A mixed-species association does not result in a stable and constant social structure. In her study, Adachi attempts to adopt the autopoiesis theory of Kawamoto (1995) in order to describe such a fugitive, momentary and ephemeral aspects of a society (for English introduction to autopoiesis theory, see Maturana and Varela 1987). Although such non-structured (corresponding to Itani's anti-structure) societies seen in mixed-species associations are often difficult to treat with our language because of their lack of structure, Adachi argues they are essential in understanding what is regarded "social" in primate studies. This is because what we actually experience as "social" in our everyday life is not often structured but rather non-structured as shown in the case of a child at the beginning.

Nishie (2008) studied the interactions of Mahale chimpanzees involved in arboreal ant fishing, and provided detailed descriptions of some events. Although ant fishing is usually regarded as cultural tool-use, Nishie's approach differed from that of current cultural studies or social learning theories of primates, which tacitly assume the transfer of information from a knowledgeable individual to an ignorant other. He reconsidered and deconstructed such transmission metaphors and instead introduced another epistemological standpoint, action-practice model. He described dynamics of the social practices at ant-fishing scenes, and by doing so, discussed that some characters such as attitude depending on others' actions, moderate exploring proposition to others, and direct reaction to such propositions, were important to realize such social situation of ant-fishing as a cultural practice of chimpanzees. Such standpoint might widen the scope of cultural primatology: cultural behaviors represented by tool use should not be treated only as a relationship between the actor and the object (e.g., ants) connected with a tool. It should be reminded that each cultural practice is embedded in ongoing social interactions in the scene.

\section{Quality of Interactions}

Strictly speaking, a phenomenon occurs only once; therefore, every phenomenon is unique. However, we usually categorize some interactions into certain types and develop appropriate terms for them. The labeled interactions that we identify can often occur in a similar fashion but differently in some contexts.

Sugawara (1980) studied the interactions of encounters among solitary male Japanese macaques at Koshima Islet. He found that "agonistic" interactions such as attack and mounting occurred more often in triads than in dyads. This shows that the occurrence of a particular type of interaction is dependent on the number of participants. Nakamura (2003), who studied chimpanzee grooming, also found such a difference: Males groomed more often in dyads and triads, whereas females groomed more often in polyads of more than five individuals. Although studies of social behavior usually treat polyadic interaction by splitting it into dyadic interactions and summarizing such decomposed dyadic interactions, the abovementioned studies imply that the number of participants at the scene affects at least the quality of interactions.

Similar types of interactions are often adopted in completely different contexts, for example, in play. Bateson (1955) observed that "two monkeys engaged in an interactive sequence of which the unit actions or signals were similar to but not the same as those of combat." Although biting and hitting may be observed in play, "the playful nip denotes the bite, but it does not denote what would be denoted by the bite." Inspired by Bateson's theory, Hayaki conducted studies on social play and other interactions among immature Japanese monkeys (Hayaki 1983) and chimpanzees (Hayaki 1985; 1990).

Another example may be sexual interaction that is not directly connected to reproduction. Kitamura (1986) referred to interactions involving non-reproductive genital contacts in bonobos as "fictional" ("kari no mono" in Japanese, for which there is no appropriate equivalent word in English). In this case, fictional implies that the behaviors acquire different characteristics although they still possess their original functions. Bonobo sexual behaviors are closely related to their original function of reproduction; however, such behaviors are often used outside the reproductive context. Thus, Kitamura argued that the analysis based on interactions as fictional occurrences should inevitably be separated from causal or psychological motive theory, and the focus should be shifted to the analysis of its formal characteristics.

The abovementioned studies often do not rely on quantitative data only but instead often employ analyses of events or stories. In addition, because each author employs her/his own original style of discourse, it is not easy to summarize the common features of these studies. However, the studies seem to share the same stance, namely, viewing society as a contingent and dynamic phenomenon rather than as a deterministic 
world. Therefore, when these researchers use quantitative data, their categorization is often more subtle than usual, and they tend to provide more than the usual amount of data required for answering a particular question, in an attempt to describe the variations observed in various scenes. Standard researchers often consider such tendencies to be redundant and difficult to understand because such studies are not the usual hypothesis-testing ones.

Such a descriptive style of research is more common in social sciences such as cultural and social anthropology or ethnomethodology. However, although primatology also deals with society, there are very few descriptive studies recently in the West. An exception is the study by King (2004), who emphasized dynamic system theory, nonlinear thinking, and qualitative research. Although the subtitle of this book is "nonvocal communication in African great apes," the use of communication is not as narrow as the conventional sense, in which case it is almost equivalent to the transfer of information from one individual to another. In her study, King uses communication to refer to the more dynamic, ever-changing, and emergent property of social interactions. A similar wider view with regard to communication is also expressed and explored by Japanese primatologists (e.g., Kitamura 1988; Hayaki 1988; Takahata 1997). Kitamura (1990) emphasized the importance of interactional synchrony as the fundamental basis for communication and tried to further elaborate his idea (Kitamura 1996, 1999) in order to connect communication among nonhuman primates to that among humans.

\section{Problems and Critiques}

As mentioned above, primate interaction studies in Japan attempt to approach primate sociality by placing greater emphasis on qualitative descriptions of interactions. This does not imply that such studies do not conduct quantitative analyses. In my understanding, currently, the only way to understand the niceties of interactions is through minute and careful description. However, as discussed above, descriptive researches do not permit easy generalizations because of the nature of the individuality of phenomena. This was perhaps a difficult point to accept in the current field of evolutionary ecology, which usually aims at concise theorization and generalization of phenomena in the world of animals. Earlier, Japanese primatology easily transgress the methodological agreement of natural sciences and even employed the methodologies in social science. This practice was repeatedly criticized even within Japan. For example, in the very early stages of Japanese primatology, Sasaki (1956) made the following criticism: "It seems to me that some of the basic concepts formed by social scientists in the course of studying human society have been too easily applied to natural society (of monkeys)" (my translation). Similarly, more than four decades later, Muroyama (1998) also offered a similar criticism: "The fundamental problem of tradi- tional Japanese primatology is the application of methodology or concepts of sociology or cultural anthropology to nonhuman primates" (my translation).

Such critiques are valid in the sense of austerity that we should not easily employ anthropomorphism. However, when we deal with the dynamism and quality of social interactions and societies, some methodologies of social sciences can be of help. But why are such methodologies permitted to only one species of primates? When we try to observe the continuities of social phenomena among primates, why must we have to adhere to the distinction of human and nonhuman? Is this not another form of anthropocentrism? Of course, we cannot directly apply the methods of sociology or cultural anthropology. It is plain that researchers greatly depend on information obtained from verbal report in such study domains, whereas primatologists can never ask their targets a question. When Itani (1985a) argued that studies of primates need "not necessarily rely on biological and reductionistic approaches but can establish original and unique methodologies and theories as a social science," he may have been thinking beyond simple anthropomorphism.

Lack of theory was also criticized within the field of Japanese primatology: "As primatology has flourished worldwide and novelty has decreased, it should be emphasized that we are at a deadlock because of the lack of theory in Japanese primatology" (Takahata 1994, my translation). With respect to the lack of theory, de Waal (2003) defended Japanese primatologists; however, it may be true that Japanese primatology could not present a theory in Sibatani's (1999) sense, namely, allowing its followers to investigate and mass-produce articles within the framework without considering the validity of the framework itself. This should be understood within the context that in the Kyoto School: theories that were easily followed by many people were of little account; instead, it was demanded that each individual researcher establish his/her own research theory from his/her own observation. Recently, Japanese researchers have begun more easily to accept and to follow dominant theories such as sociobiology and socioecology.

However, original theoretical considerations about the sociality of nonhuman primates in relation to humans also exist in Japan: Kitamura $(1982 ; 2002)$ treated the concept of incest avoidance observed in nonhuman primates with respect to the famous theory by Lévi-Strauss; he also discussed the origin of language in connection with nonhuman communication (Kitamura 1999). Yamagiwa (1994) discussed the origin of the human family from the perspective of gorilla societies; similarly, Sugawara (2002) has argued about the emotional connection of primates and humans; and Kuroda, who had studied food sharing among bonobos (Kuroda 1984), developed his idea to explore the origin of social rules or institutions without language (Kuroda 1999).

These theoretical considerations in addition to those by Imanishi and Itani (see above) are not easy to understand, and it should be noted that these researchers 
sometimes employed terms that were not from the field of biology and sometimes created their own terminology. It should also be noted that it is not very easy to theorize about purely social phenomena. This is related to the fact that in human sociology, there is no single central theoretical framework to explain the diverse social phenomena. Because researchers themselves are a part of society and because their research is closely connected to society, the research becomes self-referential and therefore, cannot be assessed in a simple fashion.

\section{Toward Understanding Dynamic Sociality}

Today, the original and traditional Japanese primatology is losing status. In the name of globalization, Japanese students are guided to write their first scientific paper in English and many of them do so (also see Asquith 2000). Writing papers in English is useful for attaining a wide range of readership and to expand beyond the narrow academic world of Japan. However, since students do this without fully considering the underlying theoretical background, and many of them simply write papers that adhere to global trends. It appears that the abstruseness of the East is now being eradicated; however, at the same time, the unique and original views of the East are also disappearing.

Although it may not be a time to make a claim regarding the uniqueness of Japanese primatology, the differences in language and cultural background still remain. In particular, it is difficult to describe minute and subtle social interactions in languages other than one's mother tongue. Descriptions that are originally rich in Japanese, once translated into English, can often become platitudes and/or simplistic (Mori 1994) if the writer does not have excellent English language skills. Some quantitative data by Japanese primatologists may be evaluated to an extent; however, ideas such as direct focus on interaction itself are rarely understood by global academics. Unless they receive such acceptance (which implies that such papers may not be accepted in international journals), few researchers are seriously willing to study such phenomena. I hope that this paper has been able to express, even to a limited extent, some of the epistemology of interaction studies in Japanese primatology, which is not part of the mainstream and continues to be sidelined.

If we accept that primates are social beings, primatology does not have to limit itself to biology (Itani 1985a), one of the natural sciences, or such a limit should not be applicable with regard to the understanding of some aspects of primate sociality. Although there is an increase in the evolutionary understanding of human behaviors and societies (e.g., Barkow et al. 1992), few researchers would insist that human societies and sociality can be understood only in the context of biology. It is possible to have an academic domain for the study of sociality in primatology or even in zoology.

Scholars are now beginning to accept that primates and other nonhuman animals have their own cultures (e.g., McGrew 2004) and have proposed terms such as "cultural primatology" (de Waal 1999) and primate “ethnography" (Wrangham et al. 1994). In such a domain of studies, methods or concepts outside of biology are sometimes employed and some descriptive studies are permitted. Because primatologists understand the richness of each primate society, it may be time to focus on a field such as "primate sociology."

\section{Acknowledgments}

The study was financially supported in part by grants from Japanese MEXT (\#16255007, \#19255008 to T Nishida and \#16770186 to $\mathrm{MN}$ ) and the Global Environment Research Fund (F-061) of the Ministry of the Environment, Japan. I thank Drs. Akio Mori, William C. McGrew, Toshisada Nishida, and an anonymous reviewer for their constructive comments and suggestions on the earlier version of the paper.

\section{References}

Adachi K (2003) Mixed-species association as a society. In: Nishida M, Kitamura K, Yamagiwa J (eds) Origin and evolution of humanity. Shôwadô, Kyoto, pp 204-282, in Japanese

Asquith P (2000) Negotiating science: internationalization and Japanese primatology. In: Strum SC, Fedigan LM (eds) Primate encounters: models of science, gender, and society. University of Chicago Press, Chicago, pp 165-183

Asquith PJ (2002) Introduction. In: A Japanese view of nature: the world of living things by Kinji Imanishi. Routledge Curzon, New York, pp. xxix-1.

Barkow JH, Cosmides L, Tooby J (eds) (1992) The adapted mind: evolution psychology and the generation of culture. Oxford University Press, Oxford

Bateson G (1955/1972) A theory of play and fantasy: a report of theoretical aspects of the project for study of the role of paradoxes of abstraction in communication. Reprinted in: Steps to an ecology of mind. The University of Chicago Press, Chicago

Boesch C (2003) Is culture a golden barrier between human and chimpanzee? Evol Anthropol 12:82-91

Bygott JD (1979) Agonistic behavior, dominance, and social structure in wild chimpanzees of Gombe National Park. In: Hamburg DA, McCown ER (eds) The great apes. Benjamin/Cummings, Menlo Park, pp 405-427

Foley RA (1996) An evolutionary and chronological framework for human social behaviour. Proc Br Acad 88:5-117

Furuichi T (1999) Evolution of sex and human evolution: from observation of bonobos. Asahi Sensho, Tokyo, in Japanese

Furuichi T (2006) Evolution of the social structure of hominoids: reconsideration of food distribution and the estrus sex ratio. In: Ishida $H$, Tuttle $\mathrm{R}$, Pickford $\mathrm{M}$, Ogihara N, Nakatsukasa M (eds) Human origins and environmental backgrounds. Springer, New York, pp 235-248

Goodall J (1971) In the shadow of man. Collins, London

Hayaki H (1983) The social interactions of juvenile Japanese monkeys on Koshima islet. Primates 24:139-53

Hayaki H (1985) Social play of juvenile and adolescent chimpanzees in the Mahale Mountains National Park, Tanzania. 
Primates 26:343-360

Hayaki H (1988) Considering chimpanzee communication. Seibutsu Kagaku 40:131-139, in Japanese

Hayaki H (1990) The human within the chimpanzee. Shôkabô, Tokyo, in Japanese

Hinde RA (1976) Interactions, relationships and social structure. Man 11:1-17

Imanishi K (1941/2002) The world of living things. Chûko Classics, Tokyo, in Japanese

Imanishi K (1951) Society before humans. Imawami, Tokyo, in Japanese

Imanishi K (1952) Evolution of humanity. In: Imanishi K (ed) Man. Mainichi Shinbunsha, Tokyo, pp 36-94, in Japanese

Imanishi K (1957) Identification: a process of enculturation in the subhuman society of Macaca fuscata. Primates 1:1-29

Imanishi K (1960) Gorilla. Bungeishunju-shinsha, Tokyo, in Japanese

Imanishi K (1966) Formation of human society. NHK Books, Tokyo, in Japanese

Itani J (1954/1971) Monkeys of Takasakiyama, Shisakusha, in Japanese

Itani J (1977) Evolution of primate social structure. J Hum Evol 6:235-243

Itani J (1980a) Social structures of African great apes. J Reprod Fertil Suppl 28:33-41

Itani J (1980b) Natural history of Turkana: inexorable people. Yûzankaku, Tokyo, in Japanese

Itani J (1981/1987) Behaviors that make social structure. Reprinted in: Evolution of primate societies. Heibonsha, Tokyo, pp 223-245, in Japanese

Itani J (1985a) Japanese primatology in retrospect and in prospect. Primate Res 1:5-14, in Japanese

Itani J (1985b) The evolution of primate social structures. Man 20:593-611

Itani J (1986) Discourse on the origin of equality. In: Itani J, Tanaka J (eds) Anthropology of Natural Societies. Academia Shuppankai, Kyoto, pp 349-389, in Japanese

Itani J (1987) Evolution of primate societies. Heibonsha, Tokyo, in Japanese

Itani J (1988) Towards new theory of communication. Kikan Jinruigaku 19(1):95-111

Itani J (1990) Mercy of nature. Heibonsha, Tokyo, in Japanese

Itani J (1991/1993) Structure and anti-structure of a society. Reprinted in: When nature smiles. Heibonsha, Tokyo, pp 187-217, in Japanese

Itani J, Nishimura A (1973) The study of infrahuman culture in Japan. In: Menzel EW (ed) Precultural primate behavior. Karger, Basel, pp 26-50

Itani J, Terashima H (2001) Vegetation map of Africa: proposal of a tentative idea. Human and Culture 15:15-18, in Japanese

Itoh N (2003) Dynamics of gathering. In: Nishida M, Kitamura K, Yamagiwa J (eds) Origin and evolution of humanity, Shôwadô, Kyoto, pp 233-262, in Japanese

Kano T (1982) The social group of pygmy chimpanzees (Pan paniscus) of Wamba. Primates 23:171-188

Kauffman S (1995/1999) At home in the universe: the search for laws of self organization and complexity (Japanese edition). Nihon Keizai Shinbunsha, Tokyo

Kawai M (1965) Newly-acquired pre-cultural behavior of the natural troop of Japanese monkeys of Koshima Islet. Pri- mates 6:1-30

Kawamoto H (1995) Autopoiesis: the third generation system. Seidosha, Tokyo, in Japanese

Kawamura S (1959) The process of sub-culture propagation among Japanese macaques. Primates 2:43-60

King BJ (2004) The dynamic dance: nonvocal communication in African great apes. Harvard University Press, Cambridge, Mass.

Kitamura K (1982) Solution to incest puzzle: Lévi-Strauss' theory viewed from primatology. Shisô 693:56-71, in Japanese

Kitamura K (1986) Pygmy chimpanzees: their 'fictional' world in the gathering. In: Itani J, Tanaka J (eds) Anthropology of natural societies. Academia Shuppankai, Kyoto, pp 43-70 in Japanese

Kitamura K (1988) What is communication? Kikan Jinruigaku 19(1):40-49, in Japanese

Kitamura K (1990) Interactional synchrony: a fundamental condition for communication. Senri Ethnol Stud 27:123-140

Kitamura K (1996) Evolution of human communication and its two themes: 'accordance with others' and 'accordance with reality'. Bunkei Ronsô of Hirosaki University 31:139-166, in Japanese

Kitamura K (1999) 'Evolution of language' viewed from communication. Studies in the Humanities (Cultural Science) of Hirosaki University 2:45-70, in Japanese

Kitamura K (2002) Reconstruction of "origin of family theory": interlocution with theory by Lévi-Strauss. In: Nishida M, Kitamura K, Yamagiwa J (eds) Origin and evolution of humanity. Shôwadô, Kyoto, pp 2-30, in Japanese

Kuroda S (1979) Grouping of the pygmy chimpanzees. Primates 20:161-183

Kuroda S (1984) Interaction over food among pygmy chimpanzees. In: Susman RL (ed) The pygmy chimpanzee: evolutionary biology and behavior. Plenum Press, New York, pp 301-324

Kuroda S (1986) From the whole to the part. In: Asada A, Kuroda S, Sawa T, Nagano K, Yamaguchi M (eds) What is scientific method. Chûko Shinsho, Tokyo, pp 49-72, in Japanese

Kuroda S (1999) Reconsidering human evolution. Ibunsha, Tokyo, in Japanese

Matsuzawa T, McGrew WC (2008) Kinji Imanishi and 60 years of Japanese primatology. Curr Biol 18:R587-R591

Maturana HR, Varela FJ (1987) The tree of knowledge: The biological roots of human understanding. Shambhala Publications, Boston

McGrew WC (2004) The cultured chimpanzee: reflections on cultural primatology. Cambridge University Press, Cambridge

McGrew WC (2007) Mahale and Gombe compared: patterns of research on wild chimpanzees in Tanzania over four decades. Afr Study Monogr 28:143-153

Mori A (1994) The meaning of agonistic behavior in a wild group of bonobos (Pan paniscus): a use of story analysis. Primate Res 10:229-251, in Japanese with English summary

Muroyama Y (1998) Another "primatology today". Seibutsu Kagaku 50:193-204, in Japanese

Nakamura M (2003) 'Gatherings' of social grooming among wild chimpanzees: implications for evolution of sociality. J Hum Evol 44:59-71 
Nakamura M (in press) Ubiquity of culture and a possibility of social inheritance of sociality among wild chimpanzees, In: Lonsdorf EV, Ross SR, Matsuzawa T (eds) The mind of the chimpanzee: ecological and experimental perspectives. University of Chicago Press, Chicago

Nakamura M, Nishida T (2006) Subtle behavioral variation in wild chimpanzees, with special reference to Imanishi's concept of kaluchua. Primates 47:35-42

Nisbett RE (2003/2004) The geography of thought: how Asians and Westerners think differently.... and why (Japanese edition). Diamond-sha, Tokyo

Nishida T (1966) A sociological study of solitary male monkeys. Primates 7:141-204

Nishida T (1968) The social group of wild chimpanzees in the Mahali Mountains. Primates 9:167-224

Nishida T (1973) The children of the mountain spirits: in search for the social structure of chimpanzees. Chikuma Shobô, in Japanese

Nishida T (1987) Local traditions and cultural transmission. In: Smuts BB, Cheney DL, Seyfarth RM, Wrangham RW, Struhsaker TT (eds) Primate societies. University of Chicago Press, Chicago, pp 462-74

Nishie H (2008) Chimpanzee culture and sociality: reconsidering "the metaphor of transmission of knowledge." Primate Res 24:73-90, in Japanese with English summary

Rendall D, Di Fore A (1995) The road less traveled: phylogenetic perspectives in primatology. Evol Anthropol 4:43-52

Rendell L, Whitehead H (2001) Culture in whales and dolphins. Behav Brain Sci 24:309-382

Rousseau JJ (1755/1972) Discours sur l'origine de l'inegalite parmi les hommes. Iwanami Bunko, Tokyo, Japanese edition

Sasaki A (1956) A doubt about methodology. Shizen 11(12):7-8, in Japanese

Sawaguchi T, Kudo H (1987) Evolutionary theories on primate social structures and behaviors. Primate Res 3:48-58, in Japanese with English summary

van Schaik CP, Deaner RO, Merrill MY (1999) The conditions for tool use in primates: implications for the evolution of material culture. J Hum Evol 36:719-741

van Schaik CP, van Hoof JARAM (1983) On the ultimate causes of primate social systems. Behaviour 85:91-117

Sibatani A (1999) Structuralistic biology. University Press of Tokyo, Tokyo, in Japanese

Sterck EHM, Watts DP, van Schaik CP (1997) The evolution of female social relationships in nonhuman primates. Behav Ecol Sociobiol 41:291-309

Sugawara K (1980) Structure of social encounter among non-troop males of Japanese macaques. Kikan Jinruigaku 11:3-76, in Japanese

Sugawara K (2002) Emotional ape=man. Kôbunsha, Tokyo, in Japanese

Sugiyama Y (2000) Looking back Japanese primatology to find a way to the future. In: Sugiyama Y (ed) Primate ecology. Kyoto University Press, Kyoto, pp 451-472, in Japanese

Sugiyama Y, Koman J (1979) Social structure and dynamics of wild chimpanzees at Bossou, Guinea. Primates 20:323-339

Takahata Y (1994) Only yesterday: reviewing the Japanese primatology of the $1980 \mathrm{~s}$ and the future. Primate Res 10:181-189, in Japanese with English summary

Takahata Y (1997) Monkey talk or what we learned about 'how monkeys communicate'. In: Tani Y (ed) Natural history of communication. Shin'yôsha, Tokyo, pp 61-82, in Japanese

Takasaki H (1999) Methodology in primatology. In: Nishida T, Uehara $\mathrm{S}$ (eds) For those who study primatology. Sekaishisôsha, pp 327-347, in Japanese

Takasaki H (2000) Traditions of the Kyoto school of field primatology in Japan. In: Strum SC, Fedigan LM (eds) Primate encounters: models of science, gender, and society. University of Chicago Press, Chicago, pp 151-164

de Waal FBM (1999) Cultural primatology comes of age. Nature 399:635-636

de Waal F (2001) The ape and the sushi master: cultural reflections of a primatologist. Basic Books, New York

de Waal FBM (2003) Silent invasion: Imanishi's primatology and cultural bias in science. Anim Cogn 6:293-299

Wikipedia (2008a) Interaction. http://en.wikipedia.org/wiki/

Interaction, accessed on 12 June 2008

Wikipedia (2008b) Social interaction. http://en.wikipedia.org/ wiki/Social_interaction, accessed on 12 June 2008

Wrangham RW (1980) An ecological model of female-bonded primate groups. Behaviour 75:262-300

Wrangham RW, de Waal FBM, McGrew WC (1994) The challenge of behavioral diversity. In: Wrangham RW, McGrew WC, de Waal FBM, Heltne PG (eds) Chimpanzee cultures. Harvard University Press, Cambridge, Mass., pp $1-18$

Yamagiwa J (1987) Intra- and inter-group interactions of an all-male group of Virunga mountain gorillas (Gorilla gorilla beringei) Primates 28:1-30

Yamagiwa J (1994) Origin of family: emergence of fatherhood. University of Tokyo Press, in Japanese

Yamagiwa J (1999) Socioecological factors influencing population structure of gorillas and chimpanzees. Primates 40:87-104 